\title{
ADVOCACY ORGANISATIONS IN CEE HEALTHCARE - DOES EXPERTISE MATTER?
}

\author{
Szczepan CZARNECKI, PhD student \\ University of Opole \\ Opole/Poland \\ Rafał RIEDEL, PhD \\ University of Opole \\ Opole/Poland \\ Emilia SZYSZKOWSKA, PhD student \\ University of Opole \\ Opole/Poland
}

\begin{abstract}
The role of expert knowledge in policy-making processes has come to occupy a prominent position in scholar debates. In addition, expertise is a wellrecognized resource, facilitating interest groups' access to decision-makers. It is expected for evidence-based knowledge to be of high importance especially in the healthcare sector. However, we still know very little about the role of expertise in healthcare policy in CEE. The region itself is not a monolith, as it covers countries at various stages of economic, social, and democratic development. This article aims to overcome this research gap by examining the importance of expertise developed and provided by interest groups operating in the healthcare field as well as the extent to which this expertise translates into their access to policy-making apparatus. By examining different types of expertise (scientific, legal, economic, and impact), the Authors provide a unique approach to the topic, presenting data gathered just before the start of the
\end{abstract}


COVID-19 pandemic, which undoubtedly revealed the importance, but also the crisis of the approach to expert knowledge.

\section{Keywords}

Advocacy; CEE; expertise; healthcare policy; interest groups.

\section{INTRODUCTION}

Healthcare policy is of the highest importance both from individual and societal points of view. Healthcare is one of the basic sectors of the economy, and health itself is one of the basic goods and elements of the well-being of the unit and the whole community. This also remains a field of endless discussion on the extent of health protection guaranteed to the population within the implementation of the right to health care as well as the welfare state-free market tensions. Every crisis, such as the one associated with coronavirus, also raises a major challenge to the functioning of the sector.

The above issues are exceptionally widely observed in the Central and Eastern Europe (CEE) region. Due to the shared post-communist experience, the specific, high-expenditure nature of the sector remains in conflict with the extremely high-level societal expectations of the level of health protection. Healthcare expenditures in the CEE region are still lower than in Western Europe. Financing of healthcare has been growing constantly since 1989, but this increase in expenditure is performed mostly by households (out-of-pocket) spendings (Wagstaff and Moreno-Serra 2009; Obrizan 2019). It is therefore certainly important to ask those who and on what basis make important decisions related to health policy. This also opens a question on the status of expertise and its quality in decision-making processes as some scholars argue that the "know-do" gap is likely as large as ever (Oliver 2006).

In times of more and more complex policy dilemmas, policymakers become more and more reliant on the institution of expertise. Expert knowledge and experience in fields as diverse as science, law, or economics are required to assist the policymakers in their decisions on public policies. Decisions regarding 
healthcare policies are supported or contested by various interested parties, who act as "transmission belts", passing by not only public preferences but also supporting analysis and evidence (Flöthe 2020). Healthcare advocacy organizations, which are in the focus of this analysis, are a relatively new phenomenon in CEE countries. In the post-communist world, the culture of political participation remains relatively weak, however, CEE healthcare interest groups (IGs) have their specifics, certainly worth studying. Among others, we still know very little about IG's usage of research evidence while accessing decision-makers. How they attempt to assert their authority to influence policymaking remains relatively underexplored in health governance literature (Cohen 2013; Townsen et al. 2019). Even less focus has been dedicated to the role of specific resources that various types of organized interest utilize in their advocacy efforts in the health industry (Contrandriopoulos 2011).

This article aims to fill this research gap by examining to what extent IGs value provided expertise and specialist knowledge as a special type of resource conditioning access to policy-making processes in the healthcare policies. Based on the rational choice and resource mobilization theories, we try to answer the question of whether expertise matters in terms of the IG type as well as different types of expertise itself. Therefore, this article is organized around two main pillars: IG's perception of the importance of provided expertise and IG's perception of access to main decision-making bodies. It contributes to the advocacy organizations' expertisation literature (Christensen and Hesstvedt 2019). Expertisation trends need deeper exploration to provide insight into advocates' efforts to exert influence in policy forums. However, a large body of expertisation literature does not essentially explore the subject of different types of expertise. Our analysis adds a novel application of expertise claims, by revealing how various types of expertise are salient for different types of healthcare advocacy actors and their access to the policy process. In general, we argue that despite growing populisms that may result in the dismissal of expertise-based decision-making, expertise still matters in CEE healthcare policy. However, we assume that the importance of expert knowledge and research evidence vary in terms of IG type and different kinds of expertise. We 
seek explanations of access patterns in variations of a type of IG's organization and resource dependencies, focusing on expertise as a key resource.

Methodologically the article relies on the results of the survey conducted among various healthcare IGs in the four selected countries: Poland, Czech Republic, Hungary, and Slovenia. Data will be analysed using both descriptive statistics and regression analysis.

The article is organized as follows: after a short overview of literature and theories on healthcare policy, IGs, and access to decision-makers and expertise, we propose the research design of our study and hypotheses. Then we present data analysis and results and conclude.

\section{THEORETICAL FRAMEWORK \& LITERATURE REVIEW}

Organized interests have been the subject of interest of public policy researchers for years while the issue of societal actors and interest representation is strongly rooted in social sciences. Scholars employed various theoretical approaches and perspectives, studying such issues as the role and function of IGs for contemporary democracies, IG's types as well as their interactions and strategies of interest representation under given institutional and structural conditions. Civil society participation is important for the legitimacy of democracy, especially in relatively young systems of the CEE region, where historically this parameter was relatively weak (Howard 2003). Therefore, it is worth exploring factors conditioning such participation, of which expert knowledge is believed to be one of the most important.

Many variables, such as institutional structures, group characteristics, and issuespecific factors, can condition IG's access to the policy-making apparatus (Dür and De Bièvre 2007). The empirical studies by Rainer Eising prove that all dimensions, such as institutional context, resource dependencies, IG's organizations, and strategic choices, can influence access patterns (2007). Various classifications regarding IG types and the nature of organized interests can be found in the literature. Some scholars oppose organizations with corporate resources to public interest groups, NGOs, and business interests 
(Beyers, Eising and Maloney 2008; Binderkrantz et al. 2014). Others make differentiation on sectional and cause groups (Stewart 1979). Sectional organizations are formed to obtain material benefits for specific groups of people and represent special interests that create concentrated costs and benefits for their supporters, e.g. business groups, trade unions, etc. Cause groups are more idealistic while acting for public interest and the public good, e.g. consumers' and patients' rights, etc (Klüver and Saurugger 2013). IGs types classifications largely correspond to each other. This article employs the most basic typology proposed by Mancur Olson in his classical study on the collective action problem (1965). Olson differentiated between concentrated and diffused interest, arguing that the latter has a weaker capacity to organize and therefore act efficiently due to the group size (majority). Large organizations may suffer from the "free-ride" problem, while individuals can benefit from the efforts of few. In contrast, concentrated minor interest has a better ability to build collective action, gather resources, like expertise, and, as a result, reach decisionmakers. This theory targets group size as the main factor, conditioning resourceability and, in the end, access. Other scholars focus additionally on the importance of IG's goals as determining strategy, arguing that IGs pursuing general interests will seek access to parliament and media, while IGs with technically complicated goals will lobby bureaucrats more intensively (Binderkrantz and Krøyer 2012). As a consequence, some scholars argue that diffused groups are more into outside strategies, while concentrated focus more on inside strategies, seeking access mostly directly to decision-makers.

As highlighted, healthcare represents a central sector for the development of nations. It is also one of the major issues in public policy studies due to its importance for society. The classical study of the comparison of European health insurance systems by Ellen Immergut concludes that it is the architecture of institutions and not the strengths and resources of IGs, that plays a crucial role in shaping healthcare policies and creation of the "rules of the game" (1992). Other approaches focus rather on specific IG's role. Christine Mahoney and Frank R. Baumgartner examined the effectiveness of the IGs coalitions in Washington, pointing out that creating such coalitions causes trouble for their members much more often than increases the chances of pursuing their interests 
and the possibility of influencing healthcare politics (2004). Michael Heaney described the factors of healthcare IG's success, arguing that they exploit their position as dispersed intermediaries between society and decision-makers (2006). Daniel Carpenter emphasized the uniqueness of healthcare policy since voters and policymakers seem to accept redistributive claims more often for health than in other policy areas. For this reason, health policy aims to achieve consensus among the key interest groups involved in the process, not to implement the best possible interventions (2012). Damien Contandriopoulos similarly argued that healthcare decisions are made primarily based on political preferences rather than evidence and research results (2011). In his later study, he stated that even despite broad political consensus among most stakeholders, the veto of a few can be an effective barrier to the implementation of coherent reforms (Contandriopoulos et al. 2018). Thomas Oliver argued more specifically that there are usually rather concentrated interests that lead decision-makers to adopt incremental policy changes than comprehensive reforms in the healthcare sector as concentrated IGs offer immediate occurrence, direct, traceable impact, and identifiable group or geographic jurisdiction (2006). Therefore, according to Oliver, the character of expertise is rather of secondary importance while the key factor is the type of organized interests providing expertise.

IGs in CEE region have their specifics. The existing literature on the role of IGs in post-communist countries explores the main aspects of the quality of democracy (Roberts 2009), the weakness of civil society and citizen participation (Howard 2003; Guasti 2016), bureaucracy and collective action patterns (Duvanova 2007), Europeanisation and democratization (Ágh 1996), social movement character (Císař 2020), political opportunity structures (Vráblíková 2014), various systems of interest representation (Fink-Hafner 2011), and, last but not least, capacity to participate in EU governance (Obradovic et al. 2008). Despite existing literature on interest groups in the CEE region, the issue of organized interests in healthcare policies in these countries remains largely uncovered. Numerous researches focus mainly on the influence of political structures on the possibility of interest representation in the health sector (Rechel and McKee 2009). Over thirty years after the transition from socialistic to market-based economies it is already clear that although the CEE region's 
countries have chosen different ways to address their healthcare challenges, they all successfully transformed from the Semashko models towards Bismarckianlike insurance systems. Although all respective countries have introduced public and universal access to healthcare for citizens with insurance covering a significant portion of the basket, out-of-pocket patient expenses remain an important funding vehicle. In this article we treat analysed countries as a whole, assuming that despite obvious differences in organization, institutional architecture, and functioning of the healthcare systems, they represent quite similar approaches towards advocacy organizations and mobilization of their resources, such as expertise, specialist knowledge, and research evidence.

The main purpose of this mobilization is IG's access to the policy-making apparatus. Scholars employ a variety of analytical lenses to examine IG's interest representation mechanisms and linkages with policy-making processes. Rational choice theory - in which this article is rooted - highlights the added value benefits when involving access strategies. Stakeholders' participation is believed to be more adequate than pure aggregative models of decision-making. One of the objectives of IGs is to seek to change the state's public policy, which becomes possible only when they gain access (formalized or not) to the decision-making process and thus can influence the decisions. It means that IGs need access to institutions or state agencies. Therefore, IGs are granted access to the policymaking process, and the political decision-makers effectively address the questions of openness and access, which define the quality of deliberation. Access acts as a two-way street in which society and politicians meet and interact. Given a series of (perhaps intractable) methodological issues with measuring influence directly - not least of all, the difficulty associated with categorically linking specific lobbying efforts to specific policy outcomes access is also a useful proxy of influence. As measuring influence is a challenge, many scholars take an alternative approach and focus rather on IG's access to policy-making apparatus (Bouwen 2002; Dür and De Bièvre, 2007).

At the core of this article is a resource mobilization theory, strongly linked with rational choice assumptions. We examine to what extent selected resources (here exclusively expertise and specialist knowledge) condition IG's access to decision-making processes. Researchers dealing with the role of resources as a 
factor conditioning the role of interest groups in shaping public policies emphasize that the importance of different resources depends on the context in which the groups take action. Organized interest literature provides many studies testing the validity of various types of resources determining the interest groups' success (Beyers and Kerremans 2007), relying on resource mobilization (McCarthy and Zald 1977), and exchange relationships theories (Berkhout 2013; Bouwen 2004). In this approach, bureaucrats and IGs interact due to the need of resources from each other. The ability to provide and use resources, as highlighted before, is strongly connected with IG's type.

Expertise and specialist knowledge, the central factor of this analysis, is a special type of IG's resource conditioning access. It remains critical both internally (for IG's members) and externally (as exchange good for decision-makers). It is therefore perceived as a key resource by some scholars, arguing that lobbying is a strategic information transmission (Austen-Smith 1993) and provision of expertise by resource-rich, concentrated minor interest is a crucial factor of their political intelligence and advantage in the political marketplace (Woll 2007; Peterson 2018). In contrast, other empirical studies prove that expertise matters and translate into outcomes mostly for IGs that use outsider strategies (Eising 2007) and this is traditionally linked rather with diffused interests. This functional aspect of expertise and other exchange goods is growing simultaneously with competition among IGs due to the growing complexity of a group's political and socio-economic environment (Beyers, Eising, and Maloney 2008).

Expertise is recognized as a key resource in knowledge-intensive sectors (Peterson 2018) and healthcare policy undoubtedly belongs to such a sphere. There is widespread support for the notion that health policies should be strongly informed by evidence. Despite this, studies consistently find that public health policies are not exclusively rational evidence-based (Smith 2013). They also include the component of cost-benefit analysis, other economic and legal limitations, values-driven politics, as well as numerous other factors and determinants.

However, one needs to remember that expertise is used as an umbrella term for a variety of different knowledge-related activities in healthcare policy 
(Grundman 2018). It may play many functions, not only as an "access good" but also as an important tool for social learning of what works and what is doable (Peterson 2018) or as a symptom of power, as many health care professionals show disregard to patient's experiential knowledge to reinforce their professional dominance (Peterson 2001). Expertise may also play both the production and consumption functions, as after the production phase it needs to be properly communicated in a form of healthcare policy-relevant results through translation and framing (Peterson 2018).

Experts are crucially important in the healthcare business for several reasons not only do they provide the democratic input legitimacy, but they also deliver the necessary knowledge, so much appreciated in technical and detailed decision making. Various scholars emphasize different types of resources and mechanisms important for the stakeholder's input into the healthcare policy decision-making process. Society-centered accounts focus on the involvement and participation of interest groups in policy-making, but it is the epistemic accounts that emphasize the engagement of experts in all the stages of the policy process (Christensen and Hesstvedt 2019). The complexity of health-related issues forces stronger reliance on scientific expertise and knowledge-based political decisions. To be effective, the governance actors need various types of knowledge and experience of relevant stakeholders.

Nevertheless, the ongoing debate about how the knowledge and expertise of key healthcare stakeholders may be most effectively incorporated into the policy-making process (Fischer et al. 2014) remains inconclusive. A growing number of issues are becoming so technical that advanced knowledge is indispensable, equally from the medical as well as from the legal or economic perspectives. The decision-makers need specialized information to understand the problem in question properly and then formulate effective remedies as well as meet public demands and deliver in an economically and legally sustainable way.

There are various reasons why stakeholders value the expertise and consequently, there are many various types of demand expertise. Purely medical knowledge is an important element of this expertise, but there are many other types of related knowledge and experience, including the economic or legal 
ones. Research-based evidence and other types of expertise influence the pathways of policymaking. However, since it is never exclusively the knowledge-driven model (Weiss 1979), other expertise types play a significant role too. Drawing on an extensive survey exercise conducted among the diverse health care sector's organized interests in four post-communist countries, we provide a typology of expertise types that are built on the demand claims.

We identify four types of expertise claims:

- Scientific - through the use of evidence, research-driven, medical knowledge-based, evidence-informed claims;

- Economic - through appeals to commercial determinants of health, cost-benefit calculations, managerial / governance effectiveness;

- Legal - built on legislative and procedural competence needed (especially however not exclusively) at the implementation phase;

- Impact assessment - scholastic expertise enabling to evaluate the specific objectives by emphasizing public benefit or cost of certain policy choices.

Taking into account the whole policy cycle, a convergence of all the abovementioned types of expertise is required, nevertheless, they are differently salient for various actors at various stages of decision making. To assess the impact of a certain solution, medical, but also economic expertise is needed. Its implementation requires legal expertise in conjunction with the two abovementioned ones. While technical experts are necessary, they should not be closed in exclusive communities, but their knowledge must be supplemented by other types of expertise enabling effective policy implementation.

\section{HYPOTHESES, RESEARCH DESIGN \& METHODS}

This study is organized around the main, starting assumption answering the question highlighted in the title that expertise matters for IG's operating the in CEE healthcare advocacy field. We exclusively focus on the phase of communication of expertise (in advance produced by a more or less competent research community) by IGs acting as policy promoters - providers. We assume 
that expertise matters as an important tool for IGs operating in healthcare policy.

Then we base this article on two hypotheses. The first (H1) highlights the importance of IG's type (concentrated/diffused) as a control variable, presenting the expertise-ability of IGs. Some scholars underline that it is important who (which IG's type) provides expertise, arguing that citizen groups are more likely to pass valuable information on public preferences to policymakers (Flöthe 2020). As a result of those findings, we predict that:

- H1: Different IGs types value provided expertise to varying degrees.

There are different theoretical expectations regarding various types of expertise as a match between the type of provided information and decision-makers' demands (Hanegraaff et al., 2019). According to Bouwen, parliamentarians who remain under relatively direct electoral control - are likely to favour political support information, while executive decision-makers are more focused on scientific and technical expertise (2004). In addition, different types of expertise are important regarding the issue/policy. Then the second hypothesis $(\mathrm{H} 2)$ focus on the correlation between the type of expertise provided by IGs and their access to decision-making:

- H2: Different types of expertise facilitate IG's access to policy-making apparatus to varying degrees.

Methodologically, we rely on the survey dataset developed within the project entitled 'OrgIntCEE - The <Missing Link>: Examining organized interests in post-communist policy-making - OrgIntCEE' conducted between February 2019 and June 2020 by the German-Polish Team. The online survey was conducted in the four different CEE countries: Czech Republic, Hungary, Poland, and Slovenia on a representative sample of interest groups operating in the three policies: energy, healthcare, and higher education. We have appointed groups on differentiated interests, such as employee organizations, NGOs, trade unions, business organizations. All of them operate on a national, major level of representativeness. In total, we have received over 400 responses with a total response rate of $34,4 \%$. The survey included numerous questions on membership structures, interest groups' resources, the degree of professionalization, and interactions of organized interests with different 
political venues. For this study, we focus exclusively on healthcare policy responses $(\mathrm{N}=176)$.

The control variable in this study is based on the basic scholar IG classification by the nature of interest: diffused/concentrated, which is well described by scholarly literature as described below. Therefore, diffused interest $(\mathrm{N}=104)$ is represented by the patients' advocacy organizations, while concentrated interest $(\mathrm{N}=72)$ by medical personnel organizations, trade unions, and employers' associations.

The dependent variable measured in this study is based on the "access" data obtained in a survey. We assume that access - both direct and indirect - to the policy-making process demonstrates not only how inclusive the authorities are, but also how powerful the concrete interests are. In our survey, to grasp the level of IG's access to decision-making, we have asked a series of questions with an ordinal scale of answers:

- How difficult to access regulatory authorities? (1. Extremely difficult 2. Difficult 3. Sometimes possible 4. Easy 5. Extremely easy)

- How difficult to access governing parties? (1. Extremely difficult 2. Difficult 3. Sometimes possible 4. Easy 5. Extremely easy)

- How would you describe your level of participation in parliamentary hearings/parliamentary committees? (1. No participation 2. Low participation 3. Occasional participation 4. High participation 5. Very high participation)

- How difficult to access opposition parties? (1. Extremely difficult 2. Difficult 3. Sometimes possible 4. Easy 5. Extremely easy)

For this analysis, we aggregate those four dimensions of access. Therefore, our dependent variable - access to the policy-making apparatus - is a means of access to regulatory authorities, parliament, governing political parties and opposition parties, and the frequency of the consultations.

Our independent variables taken into account are the importance of expertise as well as specific types of expertise. To measure this, we have asked a series of questions on the importance of provided expertise/information on their influence on policy using a 1-3 ordinal scale: 
- How would you indicate the importance of provided expertise/information on your influence on policy? (1. Unimportant 2. Somewhat important 3. Very important).

We have asked our respondents to indicate - one by one - the importance of different types of expertise: scientific, economic, legal, and impact. To simplify the results and properly address the research question, we have aggregated the "somewhat important" and "very important" answers, which gave us only dual scale with the two types of responses: "important" and "unimportant". Then we also differentiated among the types of interest using the control variable.

We decided to analyse our data using descriptive statistics, to picture the general trends observable in the importance of expertise in CEE healthcare policy. Additionally, to grasp the causal mechanisms between a provision of specific types of expertise and aggregated IG's access to policy-making apparatus, we have conducted linear regression analysis. "Access" is a continuous variable, previously measured on designed five-point Likert scales which was recoded to values from 1 to 100. To measure which organizations are diffuse or concentrated, based on Olson's logic we created a dummy variable which takes the value 0 for diffuse organizations (patients' organizations, health care promotion and prevention groups) and 1 for concentrated groups (doctors, medical professions, pharmaceutical groups). To measure the importance of the specific expertise (scientific, legal, economic, and impact) we created binary variables to test whether expertise holders that assess particular expertise as important enjoy better access to policymakers. All the expertise variables take values 1 for expertise assessed as important and 0 for not important.

\section{DATA ANALYSIS \& RESULTS}

By research questions, starting assumptions, and hypotheses, we begin our data analysis with a short overview of the importance of expertise declared by IGs in our survey with no differentiation on the group type. 


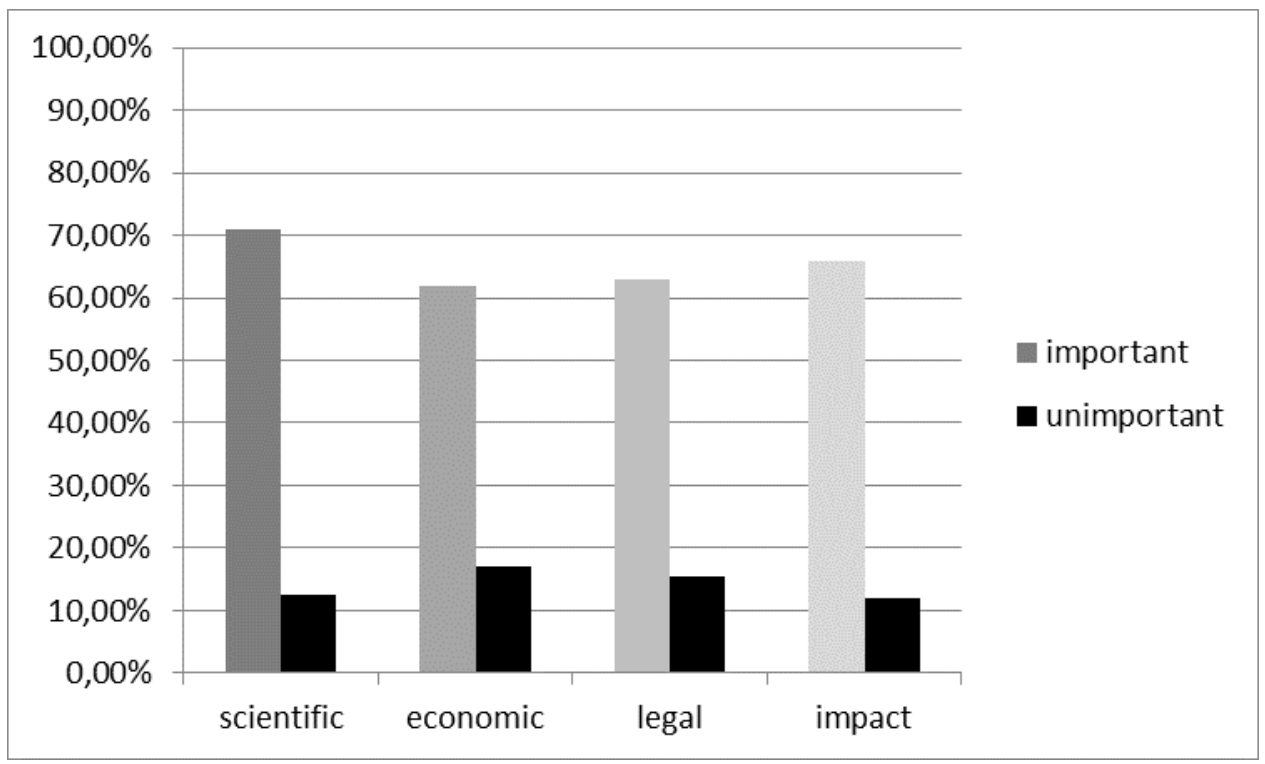

Figure 1. Importance of provided expertise (scientific, economic, legal, impact) indicated by IGs. Source: Own elaboration.

It is clear that expertise matters and this is a fact in the case of all expertise types. However, it is quite easy to indicate the most important types of expertise in CEE healthcare: respondents perceive scientific and impact expertise types as the most "important". Additionally, those two types of expertise were the least indicated to be "unimportant".

Regarding the first hypothesis, using descriptive statistics we found that despite theoretical expectations on the advantage of concentrated interests inefficient translation, and provision of expertise (Peterson 2018) - IGs value very little in terms of assessment of the importance of different types of developed and provided expertise. In general, concentrated interests value expertise more, however, this difference is not substantial. On the other hand, the greater differences show up in the case of assessment of unimportance of expertise. Diffused interests indicated unimportance less frequently. Therefore, our hypothesis (H1) on the difference between IG types of interests in expertise - importance assessment is verified only partially. 


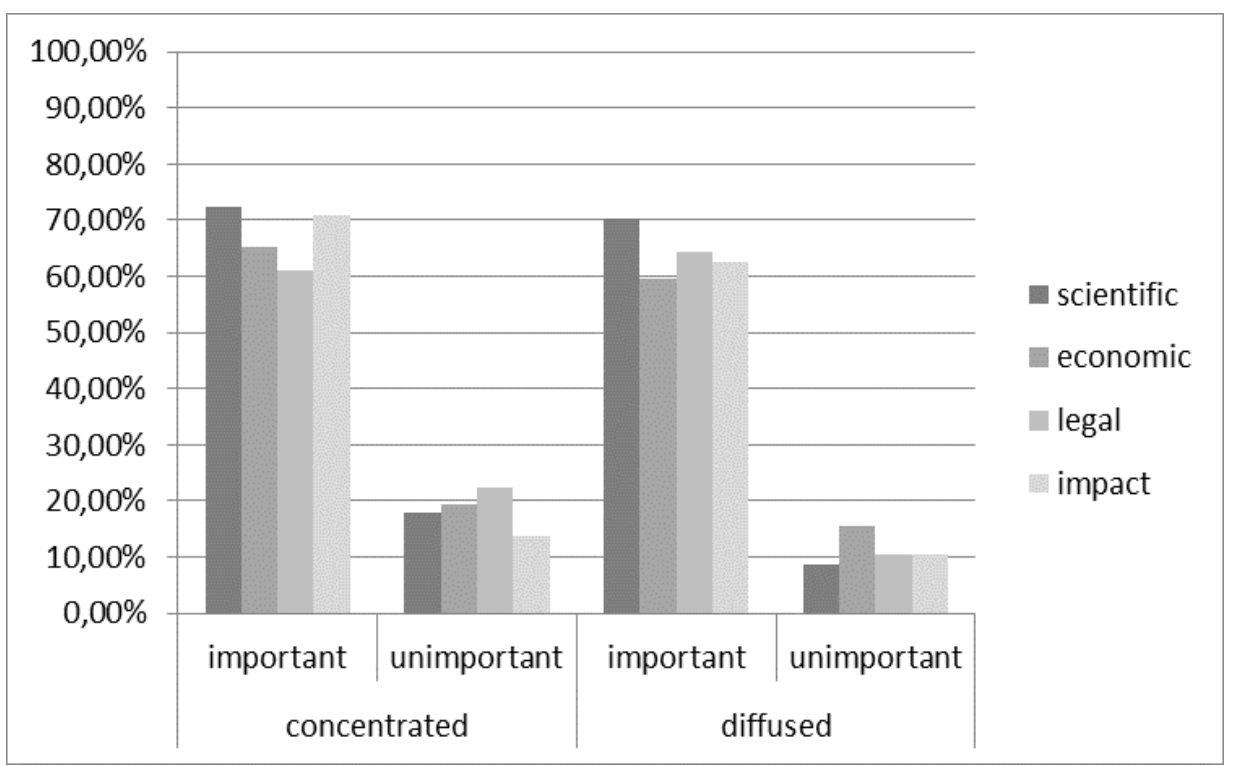

Figure 2. Importance of provided expertise with differentiation on the type of expertise (scientific, economic, legal, impact) and IG's type (concentrated, diffused). Source: Own elaboration.

Our results show that in the case of concentrated IGs the frequency of assessment of expertise as unimportance is higher than in the case of diffused IGs. Concentrated IGs value scientific and impact expertise the most. The legal expertise is rated the lowest (most "unimportant" ratings). On the opposite, for diffused IGs the legal type of expertise turned out to be the second most important expertise. The first is, similarly to concentrated IG's, scientific expertise.

In the next phase of our study, we measured the role of four different types of expertise in accessing political institutions using regression analysis. We conducted linear regressions to analyse the impact of IG type (diffuse/concentrated) and expertise type on access. We developed six models based on group type and expertise type. In table 1, in all models, we tested whether there is a difference between group type and access to the policy- 
making apparatus in the healthcare sector. Our data show that group type can make a difference in access, even as we found no statistically significant difference between IG types: the coefficient variable ranges from 0,086 to $-0,283$ in our models, showing that expertise type importance assessment changes direction and becomes negative when tested with added economic, legal and impact expertise, which make impressions, that specific expertise importance may have an impact on diffuse IG's access.

\begin{tabular}{|c|c|c|c|c|c|}
\hline & (1) & (2) & (3) & (4) & (5) \\
\hline $\begin{array}{l}\text { Concentrated } \\
\text { interests }\end{array}$ & $\begin{array}{r}0,500 \\
(0,753)\end{array}$ & $\begin{array}{l}-0,168 \\
(0,508)\end{array}$ & $\begin{array}{l}-0,218 \\
(0,518)\end{array}$ & $\begin{array}{l}-0,187 \\
(0,513)\end{array}$ & $\begin{array}{l}-0,283 \\
(0,564)\end{array}$ \\
\hline Scientific Exp & $\begin{array}{l}1,415^{* *} \\
(0,667)\end{array}$ & & & & $\begin{array}{l}0,925 \\
(0,881)\end{array}$ \\
\hline Economic Exp. & & $\begin{array}{l}0,856 \\
(0,556)\end{array}$ & & & $\begin{array}{l}0,722 \\
0,843\end{array}$ \\
\hline Legal Exp. & & & $\begin{array}{l}0,862 \\
(0,597)\end{array}$ & & $\begin{array}{l}0,222 \\
0,793\end{array}$ \\
\hline Impact Exp. & & & & $\begin{array}{l}1,007 \\
(0,663)\end{array}$ & $\begin{array}{l}0,103 \\
0,970\end{array}$ \\
\hline$R^{2}$ & 0,120 & 0,147 & 0,129 & 0,136 & 0,163 \\
\hline $\mathrm{N}$ & 174 & 174 & 175 & 175 & 173 \\
\hline
\end{tabular}

Table 1. Importance of provided expertise and IG's type on the access to the policy-making apparatus. Source: Own elaboration. Regression analysis. Standard errors in parentheses ${ }^{*} \mathrm{p}<0.05,{ }^{* *} \mathrm{p}<0.01,{ }^{* * *} \mathrm{p}<0.001$.

As a next step testing the $\mathrm{H} 2$ hypothesis stating that different types of expertise translate into higher levels of access to policy-making apparatus we tested different types of expertise. In the second model, we tested whether scientific expertise plays a role in access. The scientific expertise coefficient is positive and significant taking a value of 1,415 . Thus, we can expect organizations that are stating the importance of scientific expertise to enjoy better access to the political apparatus. However, three other types of expertise are insignificant, thus we can 
expect that economic, legal, and impact expertise are much less important in access to the political process for the healthcare IGs, however, the coefficient is positive, just insignificant. Therefore, our data clearly show that expertise matters, and IGs that assess the importance of scientific expertise can enjoy better access to the policy-making apparatus.

\section{CONCLUSIONS}

Given the government administration lacks sufficiently specialized knowledge, IGs aim to provide technical information and advice of medical, economic, and legal nature. The use of expertise goes beyond what is variously referred to as stakeholders' involvement, participation, or engagement. These processes and phenomena contribute to the policy-choices legitimacy, representativeness, accountability, and transparency (Mazanderani et al, 2020), but they do not necessarily need to be neutral. The experts' perspectives may differ, depending on what kind of knowledge and experience they bring in. The key question is how to strike a balance between science and politics?

By examining different types of expertise (scientific, legal, economic, and impact expertise), this article provides a unique approach to the topic of expertise as a resource facilitating IG's access to decision-makers. Our research proves the hunger for credibility and basing the decision-making process on neutral and objective facts, as scientific expertise is the most correlated with IG's access to policy-making apparatus and legal and economic expertise is valued and correlated with access to a lesser extent.

We also found that there is no substantial asymmetry between IG types in terms of the perceived importance of expertise. All types of expertise are valued by both diffused and concentrated interests to a very similar degree. This proves the general assumption that expertise matters in CEE healthcare, playing a crucial role in exchanging goods between IGs and decision-makers.

When considering the issue of the importance of expert knowledge in healthcare policies in the post-communist region in the context of international relations, it is impossible to ignore the topic of Europeanization. Due to the process of 
European integration and the transfer of competencies from the national to the European level, the decision-making process at individual national levels has often changed in the pre-accession period. At the same time, it changed the political landscape in which IGs operate (Grabbe 2011). This also applies to healthcare policy, which, although still in the hands of national states, is large more or less directly - shaped by pressure from the European Union (Piotrowska 2020). This pressure concerns, inter alia, the importance of expert knowledge in shaping healthcare policies of the countries in the region, which not only had to adapt their legislation, but also create institutions based on expert knowledge, such as health technology assessment offices. On the other hand, the Europeanization processes contributed to the increase in the number and activity of IGs themselves (Rozbicka et al. 2021). As a consequence, the groups strengthened their professionalization, developed competencies, and international communication. Consequently, their ability to use resources, such as expert knowledge of various kinds, while accessing decision-makers, has increased (Holzinger and Knill 2005). In this light, the European Union can be seen as a giant socialization platform that actively promotes rules, norms, practices, and structures of meaning to which member states (various actors, including the IGs) are exposed and which they have to incorporate into their domestic structures (Börzel and Risse 2012).

Our research shows unequivocally that on the supply and demand side of healthcare expertise, stakeholders appreciate the value of various types of expertise. At the same time, it is the most objectified scientific expertise that seems to facilitate access to decision-makers to the greatest extent. This discovery has important implications for both researchers and political actors, as basing decisions on facts, and not political opinions nor polls can be an important element in the fight against pandemic disinformation and growing populism, for which CEE has become a testing ground (Hamiti 2021). 


\section{ACKNOWLEDGEMENTS}

This research was conducted as a part of the research project 'The "Missing Link": Examining organized interests in post-communist policy making' of the University of Konstanz, Germany and the University of Opole, Poland funded by the Beethoven 2 Polish-German Funding Initiative of the Deutsche Forschungsgemeinschaft and the Narodowe Centrum Nauki, grant no. 2016/23/G/HS5/01001.i. We sincerely thank both organizations for funding.

\section{REFERENCES}

- Ágh, Attila. 1996. "Meso-politics in Central Europe: fighting with the infantile disease in Europeanisation and democratization." The Second Steps, edited by Attila Ágh and Gabriella Ilonszki, Budapest: Hungarian Centre of Democracy Studies.

- Austen-Smith, David. 1993. "Information and Influence: Lobbying for Agendas and Votes". American Journal of Political Science. 37(3): 799-833.

- Beyers, Jan and Bert Kerremans. 2007. "Critical resource dependencies and the Europeanization of domestic interest groups". Journal of European Public Policy. 14(3): 460-481.

- Beyers, Jan, Rainer Eising, and William Maloney. 2008. "Researching Interest Group Politics in Europe and Elsewhere: Much We Study, Little We Know?" West European Politics. 31(6): 1103-1128.

- Berkhout, Joost. 2013. "Why interest groups do what they do: Assessing the explanatory potential of 'exchange' approaches". Interest Groups $\mathcal{E}$ Advocacy. 2(2): 227-250.

- Binderkrantz, Anne S., Peter M. Christiansen, Helen H. Pedersen. 2014. “A Privileged Position? The Influence of Business Interests in Government Consultations". Political Research Quarterly. 24(4): 879-896. 
- Binderkrantz, Anne S., Simone Krøyer. 2012. “Customizing strategy: Policy goals and interest group strategies". Interest Groups \& Advocacy. 1(1): 115138.

- Börzel, Tanja A. and Thomas Risse. 2012. "From Europeanisation to Diffusion: Introduction". West European Politics. 35(1): 1-19.

- Bouwen, Pieter. 2002. "Corporate Lobbying in the European Union: the Logic of Access". Journal of European Public Policy. 9(3): 365-390.

- Bouwen, Pieter. 2004. "Exchanging access goods for access: A comparative study of business lobbying in the European Union institutions". European Journal of Political Research. 3(43): 337-369.

- Christensen, Johan and Stine Hesstvedt. 2019. "Expertisation or greater representation? Evidence from Norwegian advisory commissions". European Politics and Society. 20(1): 83-100.

- Císař, Ondřej. 2020. "Social Movement Diffusion in Eastern Europe." Routledge Handbook of Contemporary European Social Movements. edited by Cristina Flesher Fominaya, Ramón A. Feenstra, 237-250. London and New York: Routledge.

- Carpenter, Daniel. 2012. "Is Health Politics Different?". Annual Review of Political Science. 15: 287-311.

- Cohen, Nissim. 2013. "The power of expertise? Politician-bureaucrat interactions, national budget transparency and the Israeli health care policy". Policy Studies. 34(5-6): 638-654.

- Contandriopoulos, Damien. 2011. "On the Nature and Strategies of Organized Interests in Health Care Policy-Making". Administration \& Society. 43(1): 45-65.

- Contandriopoulos, D., Astrid Brousselle, Catherine Larouche, Mylaine Breton, Michèle Rivard, Marie D. Beaulieu, Jeannie Haggerty, Geneviève Champagne, and Mélanie Perroux 2018. "Healthcare reforms, inertia polarization and group influence". Health Policy. 122(9): 1018-1027.

- Dür, Andreas and Dirk de Bièvre. 2007. "Inclusion without influence? NGOs in European Trade Policy". Journal of Public Policy. 27(1): 79-101. 
- Duvanova, Dinissa. 2007. "Bureaucratic Corruption and Collective Action: Business Associations in the Postcommunist Transition". Comparative Politics. 39(4): 441-461.

- Eising, Rainer. 2007. "Institutional Context, Organizational Resources, and Strategic Choices: Explaining Interest Group Access in the European Union". European Union Politics. 11(3): 329-369.

- Fink-Hafner, Danica. 2011. "Interest representation and postcommunist parliaments over two decades". The Journal of Legislative Studies. 17: 215-233.

- Fischer, Arnout R. H., Meike T. A. Wentholt, Gene Rowe, and Lynn J. Frewer. 2014. "Expert involvement in policy development: A systematic review of current practice". Science and Public Policy. 41: 323-343.

- Flöthe, Linda. 2020. "Representation through information? When and why interest groups inform policymakers about public preferences". Journal of European Public Policy. 27(4): 528-546.

- Grundmann, Robert. 2009. "The role of expertise in governance processes". Forest Policy and Economics. 11: 398-403.

- Grundman, Robert. 2018. "The rightful place of expertise". Social Epistemology. 32(6): 372-386.

- Hanegraaff, Marcel, Jorik Vergauwen, and Jan Beyers. 2019. “Should I stay or should I go? Explaining variation in non-state actor advocacy over time in global governance". Governance. 1-18: 287-304.

- Heaney, Michael T. 2006. "Brokering health policy: coalitions, parties, and interest group influence". Journal of Health Politics, Policy and Law. 5: 887944.

- Howard, Marc M. 2003. The Weakness of Civil Society in Post-Communist Europe. Cambridge: Cambridge University Press.

- Grabbe, Heather. 2001. "How does Europeanization affect CEE governance? Conditionality, diffusion and diversity". Journal of European Public Policy. 8(6): 1013-1031.

- Guasti, Petra. 2016. "Development of citizen participation in Central and Eastern Europe after the EU enlargement and economic crises". Communist and Post-Communist Studies. 49(3): 219-231. 
- Hamiti, Urtak. 2021. "People demand change now: populism as a governing and decision-making ideology". Europolity. Continuity and Change in European Governance. 15(1): 153-175.

- Holzinger, Katharina and Knill, Christoph. 2005. "Causes and conditions of cross-national policy convergence." Cross-national Policy Convergence: Causes, Concepts, and Empirical Findings. edited by Christoph Knill. 775-796. New York: Taylor and Francis.

- Immergut, Ellen. 1992. Health Politics: Interests and Institutions in Western Europe. Cambridge: Cambridge University Press.

- Klüver, Heike, Sabine Saurugger. 2013. “Opening the black box: The professionalization of interest groups in the European Union". Interest Groups \& Advocacy. 2(2): 185-205.

- Mahoney, Christine, Frank R. Baumgartner. 2004. "The determinants and effects of interest-group coalitions". APSA conference papers.

- Mazanderani, Fadhila, Tehseen Noorani, Tehseen Noorani, Farzana Dudhwala, Zara Thokozani Kamwendo. 2020. "Knowledge, evidence, expertise? The epistemics of experience in contemporary healthcare". Evidence \& Policy: A Journal of Research, Debate and Practice. 16(2): 1-18.

- McCarthy, John D., Mayer N. Zald. 1977. "Resource Mobilization and Social Movements: A Partial Theory". American Journal of Sociology. 82(6): 12121241.

- Obradovic, Daniela, Heiko Pleines. 2008. "The Capacity of Central and East European Interest Groups to Participate in EU Governance". Changing Europe. 3.

- Obrizan, Maksym. 2019. "Diverging trends in health care use between 2010 and 2016: Evidence from three groups of transition countries". Economic Systems. 13(1): 19-29.

- Oliver, Thomas R. 2006. "The politics of public health policy". Annu. Rev. Public Health. 27: 195-233.

- Olson, Mancur. 1965. "The logic of collective action: Public goods and the theory of groups". Harvard economic studies: v. 124. Cambridge, Mass., Harvard University Press. 
- Peterson, Barbara. 2001. "Myth of empowerment in chronic illness". Journal of Advanced Nursing. 34(5): 574-581.

- Peterson, Mark A. 2018. "In the Shadow of Politics: The Pathways of Research Evidence to Health Policy-Making". Journal of Health Politics, Policy and Law. 43(3): 341-376.

- Piotrowska, Emilia. 2020. “Czy w Unii Europejskiej powstanie nowa polityka zdrowotna?" Jaka przyszłość Unii Europejskiej? Wyzwania, problemy, szanse. edited byUrszula Kurczewska. 119-130. Warsaw: Oficyna Wydawnicza SGH.

- Rechel, Berndt, Martin McKee. 2009. "Health reform in central and eastern Europe and the former Soviet Union". The Lancet, 374(9696): 1186-1195.

- Roberts, Andrew 2009. The Quality of Democracy in Eastern Europe: Public Preferences and Policy Reforms. Cambridge: Cambridge University Press.

- Rozbicka, Patrycja, Paweł Kamiński, Meta Novak, and Vaida Jankauskaitè. 2021. Achieving Democracy Through Interest Representation. Interest Groups in Central and Eastern Europe. London: Palgrave MacMillan.

- Smith, Katherine 2013. "Understanding the Influence of Evidence in Public Health Policy: What Can We Learn from the 'Tobacco Wars'?". Social Policy and Administration. 47(4): 382-398.

- Stewart, John D. 1979. British Pressure Groups, Their Role in Relation to the House of Commons. Greenwood Publishing Group.

- Townsen, Belinda, Ashley Schram, Ronald Labonté, Fran Baum, Sharon Friel, S. 2019. "How do actors with asymmetrical power assert authority in policy agenda setting? A study of authority claims by health actors in trade policy". Social Sciences \& Medicine. 236: 1-9.

- Triantafillou, Peter. 2015. "The Politics of Neutrality and the Changing Role of Expertise in Public Administration". Administrative Theory \& Praxis. 37: 174-187.

- Wagstaff, Adam, Rodrigo Moreno-Serra. 2009. "Europe and Central Asia's great post-communist social health insurance experiment: Aggregate impacts on health sector outcomes". Journal of Health Economics. 28(2): 322340. 
- Weiss, Carol H. 1979. "The Many Meanings of Research Utilization". Public Administration Review. 39(5): 426-31.

- Woll, Cornelia. 2007. "Leading the Dance? Power and Political Resources of Business Lobbyists". Journal of Public Policy. 27(1): 57-78.

- Vráblíková, Katharina. 2014. "How Context Matters? Mobilization, Political Opportunity Structures and Non-Electoral Political Participation in Old and New Democracies". Comparative Political Studies. 47(2): 203-229. 